\title{
Identification of Fasciola Species Isolates from Nghe An Province, Vietnam, Based on ITS1 Sequence of Ribosomal DNA Using a Simple PCR-RFLP Method
}

\author{
Do Ngoc Anh $\left(\mathbb{D},{ }^{1}\right.$ Le Tran Anh, ${ }^{1}$ Le Quoc Tuan, ${ }^{1}$ Nguyen Duy Bac, ${ }^{2}$ Tran Viet Tien, ${ }^{3}$ \\ Vu Thi Binh Phuong, ${ }^{4}$ Tran Thanh Duong, ${ }^{5}$ Nguyen Khac Luc, ${ }^{1}$ and Nguyen Ba Quang ${ }^{6}$ \\ ${ }^{1}$ Department of Medical Parasitology, Vietnam Military Medical University, Hanoi 100000, Vietnam \\ ${ }^{2}$ Department of Anatomy, Vietnam Military Medical University, Hanoi 100000, Vietnam \\ ${ }^{3}$ Department of Infectious Diseases, Vietnam Military Medical University, Hanoi 100000, Vietnam \\ ${ }^{4}$ Department of Medical Parasitology, Thai Binh University of Medicine and Pharmacy, Thai Binh 410000, Vietnam \\ ${ }^{5}$ National Institute of Malariology Parasitology and Entomology Vietnam, Hanoi 100000, Vietnam \\ ${ }^{6}$ Department of Laboratory Medicine, Vietnam National Hospital of Acupuncture, Hanoi 100000, Vietnam
}

Correspondence should be addressed to Do Ngoc Anh; dranhk61@gmail.com

Received 5 September 2018; Accepted 22 November 2018; Published 4 December 2018

Academic Editor: Bernard Marchand

Copyright (C) 2018 Do Ngoc Anh et al. This is an open access article distributed under the Creative Commons Attribution License, which permits unrestricted use, distribution, and reproduction in any medium, provided the original work is properly cited.

\begin{abstract}
Fascioliasis-a disease caused by Fasciola spp. (Platyhelminthes: Trematoda: Digenea) -is considered as the most important helminthic infection of bovine, sheep, and buffalo in Vietnam. The aim of this study is to detect the genotype of Fasciola spp. isolated from bovine and buffalo in the Nghe An province, central Vietnam, using PCR-RFLP and sequence analysis of the first nuclear ribosomal internal transcribed spacer (ITS1). Adult Fasciola spp. were isolated from bile ducts of bovine and buffalo in Nghe An province, Vietnam. Overall, 96 adult flukes from livers of slaughtered animals were collected from abattoirs of different areas. They included 7 samples from infected bovine and 89 samples from infected buffalo. 96/96 samples were identified as Fasciola species by ITS1 of rDNA. In this study, a PCR-RFLP method was used to distinguish between F. hepatica and F. gigantica in ITS1 of rDNA (680 bp) with RsaI restriction enzyme. RFLP pattern with RsaI produced a consistent pattern of 360, 100, and 60 bp fragments in F. hepatica, whereas F. gigantica worms had a profile of 360, 170, and $60 \mathrm{bp}$ in size, respectively. The results showed that using PCR-RFLP based on the first internal transcribed spacers (ITS1) of the ribosomal RNA revealed that 93 out of 96 isolates were of Fasciola gigantica type, whereas three isolates presented an intermediate Fasciola. In the present study, F. gigantica and intermediate form were coexisting in bovine and buffalo in the Nghe An province of central Vietnam, whereas F. hepatica was not detected.
\end{abstract}

\section{Introduction}

Fascioliasis, a disease caused by the liver flukes of the genus Fasciola, is one of the most important food- and waterborne parasitic zoonoses. F. hepatica and F. gigantica are two main species which infect humans and animals. F. hepatica has a worldwide distribution and both species exist in the tropical and subtropical regions of Africa and Asia [1, 2]. Differentiation of these two species, based on morphological characteristics such as the ratio of body length to width, is difficult due to the variation in their size, particularly with respect to the age of flukes, involved host species, and fixation techniques used [3]. Because of the limitations of morphological methods, several molecular approaches, using different molecular targets, have been developed for the differentiation of F. hepatica and F. gigantica [4].

Molecular approaches can be properly distinguished by DNA sequencing of first internal transcribed spacers (ITS1), ITS2, and 28S ribosomal ribonucleic acid genes [5-7]. Several studies using ITS1 of rDNA showed that $F$. hepatica, $F$. gigantica, and their intermediate forms exist in different countries including Vietnam [8-10]. Nevertheless, no reports in bovine and buffalo from Nghe An province exist. This province is located in the centre of Vietnam. Previously, the 


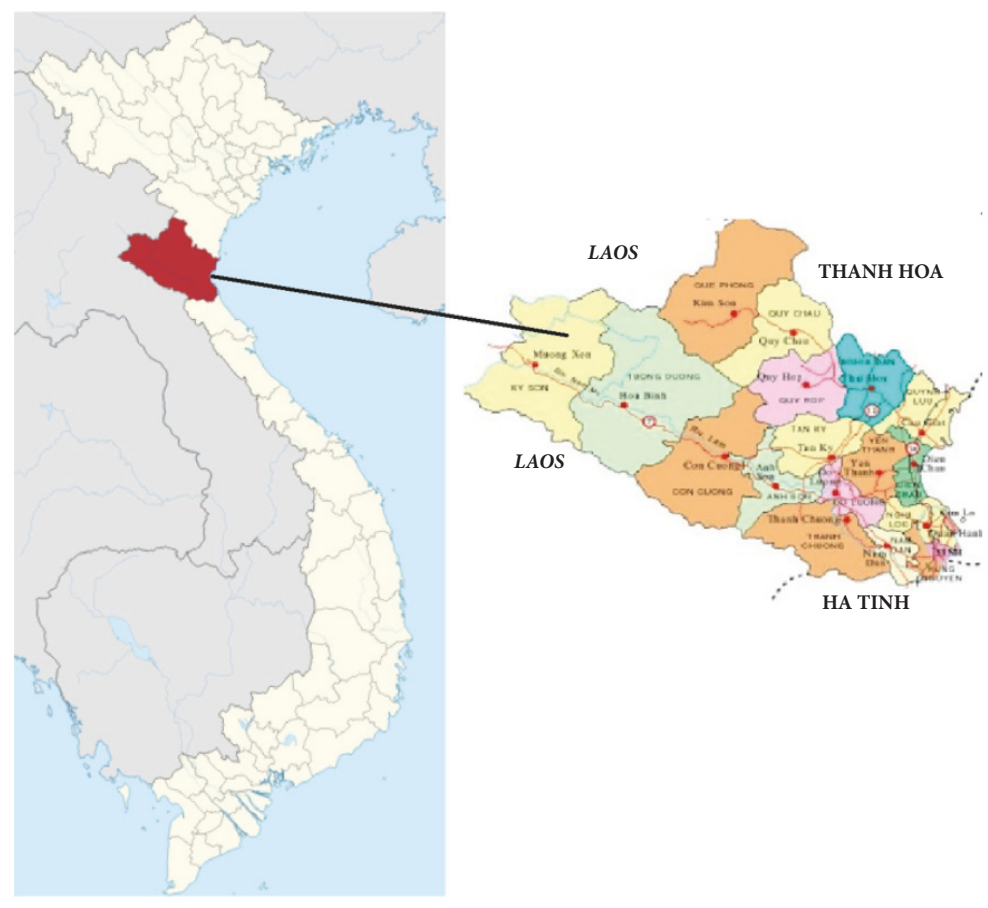

(a)

(b)

FIgURE 1: Map of Vietnam (a). Nghe An province, central Vietnam (b).

Nghe An province has been known as an important endemic area for fasciolosis in bovine [11], but very limited data is available on molecular characterization of Fasciola spp. of buffalo in this province.

Therefore, this study has been performed to detect the genotype of Fasciola spp. isolated from bovine and buffaloes in the Nghe An province, central Vietnam, using PCR-RFLP and sequence analysis of the first nuclear ribosomal internal transcribed spacer (ITS1).

\section{Materials and Methods}

2.1. Flukes. Adult flukes ( 89 flukes from 5 buffalo and 7 flukes from one bovine) were isolated from bile ducts at slaughterhouses from the Nghe An province in Vietnam (Figure 1), where human cases of fasciolosis have been recently reported. Flukes were washed extensively in physiological saline and subsequently fixed in $70 \%$ ethanol and preserved at $4^{\circ} \mathrm{C}$ until extraction of genomic DNA.

2.2. DNA Extraction. Approximately $25 \mathrm{mg}$ tissue samples were removed from each adult fluke. Total DNA was extracted using QIAamp DNA Mini Kit (No. 51304, Qiagen, Germany) according to the manufacturer's instructions. Extracted DNA was diluted in double distilled water and maintained at $-20^{\circ} \mathrm{C}$ until used in the PCR.

2.3. PCR Amplification. To amplify an approximate $680 \mathrm{bp}$ region of the ITS1 sequence, PCR was performed using a set of ITS1-F (5'-TTG CGC TGA TTA CGT CCC TG-3) and ITS2-R (5'-TTG GCT GCG CTC TTC ATC GAC-3') (Integrated DNA Technologies, USA) as sense and antisense primers (Itagaki et al., 2005) [12], respectively. Total volume of PCR reaction was $50 \mu \mathrm{l}$ containing $5 \mu \mathrm{l}$ of DNA solution, $25 \mu \mathrm{l}$ mastermix 2X (Thermo Fisher Scientific, USA), 1.0 $\mu \mathrm{l}$ of each primer $(0.2 \mu \mathrm{M})$, and $18.0 \mu \mathrm{l}$ of distilled water. PCR amplification was performed in Thermo Mastercycler Gradient (Thermo Fisher Scientific, USA). The reaction cycle was as follows: an initial denaturation step at $94^{\circ} \mathrm{C}$ for 5 minutes, followed by 35 cycles of $94^{\circ} \mathrm{C}$ for 30 seconds (denaturation), $55^{\circ} \mathrm{C}$ for 30 seconds (annealing), and $72^{\circ} \mathrm{C}$ for 60 seconds (extension) and a final extension of $72^{\circ} \mathrm{C}$ for 15 minutes.

2.4. Restriction Fragment Length Polymorphism (RFLP) Analysis. RFLP was performed according to the method described by Ichikawa $\mathrm{M}$ et al. to distinguish $F$. hepatica from F. gigantica in ITS1 with RsaI enzyme [8]. To perform RFLP assay, total volume of $16 \mu \mathrm{l}$, including $5 \mu \mathrm{l}$ of ITS1 PCR product, was added with $1 \mu \mathrm{l}$ of RsaI, $1 \mu \mathrm{l}$ of 10X Tango buffer (Thermo Fisher Scientific, USA), and $9 \mu$ l of distilled water. The tubes were incubated at $37^{\circ} \mathrm{C}$ for 12 hours to ensure full cutting of fragments, and RsaI was heat-inactivated at $65^{\circ} \mathrm{C}$ for $15 \mathrm{~min} .6 \mu \mathrm{l}$ of each product and $1 \mu \mathrm{l}$ of loading dye buffer were electrophoresed on $2 \%$ agarose gel in TBE buffer at $100 \mathrm{~V}$ for $60 \mathrm{~min}$ and visualized by UV illumination (UVP, Canada) after ethidium bromide staining. The size of each band was determined by a 50 bp plus ladder molecular weight marker (Thermo Fisher Scientific, USA). DNA types of Fasciola spp. were distinguished according to fragment patterns, three bands of 360,100 , and $60 \mathrm{bp}$ fragments in $F$. 


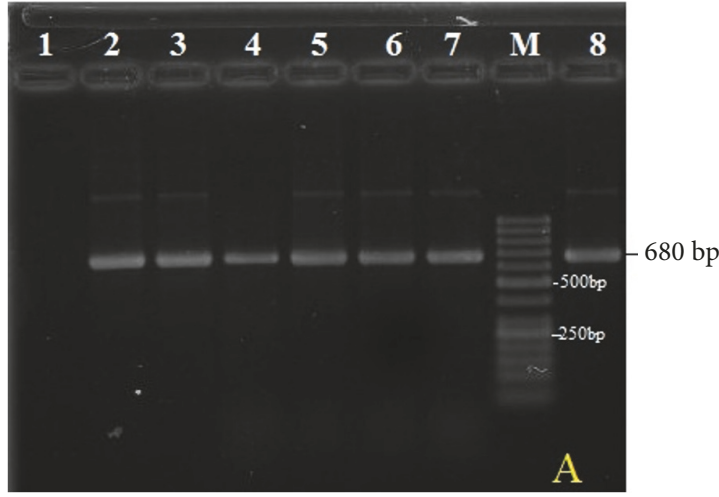

(a)

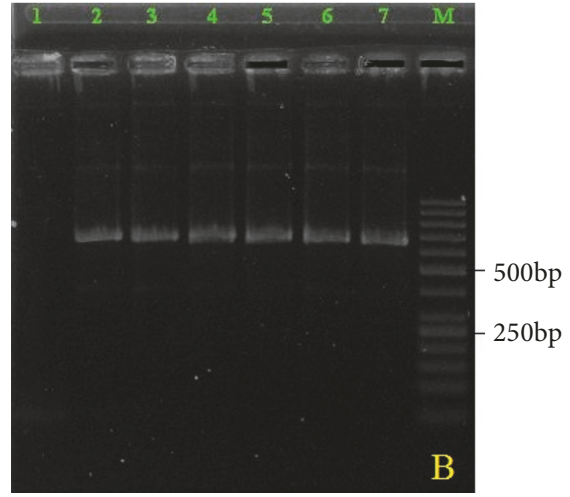

(b)

FIGURE 2: PCR patterns of amplified ITS1 ribosomal region. Lane M: 50 bp ladder molecular weight marker; lane 1 (a, b): negative control; lanes 2-8 (a) and 2-7 (b) denoted to different fluke samples amplified as a single band of 680 bp of bovine and buffalo in Nghe An province.

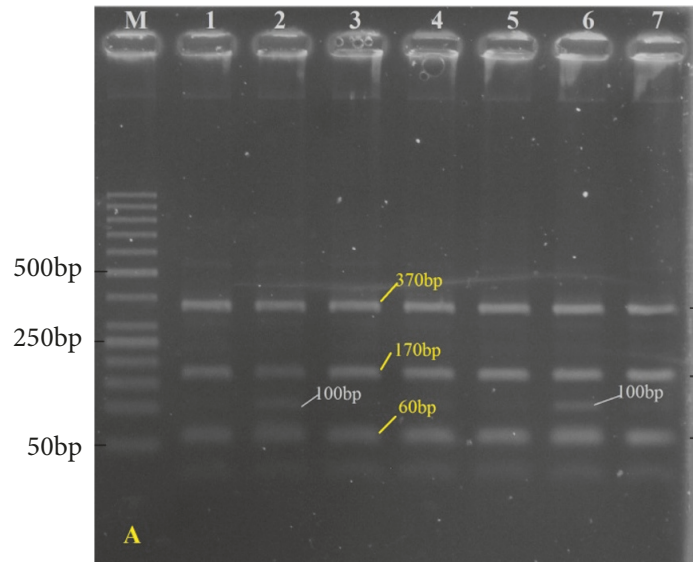

(a)

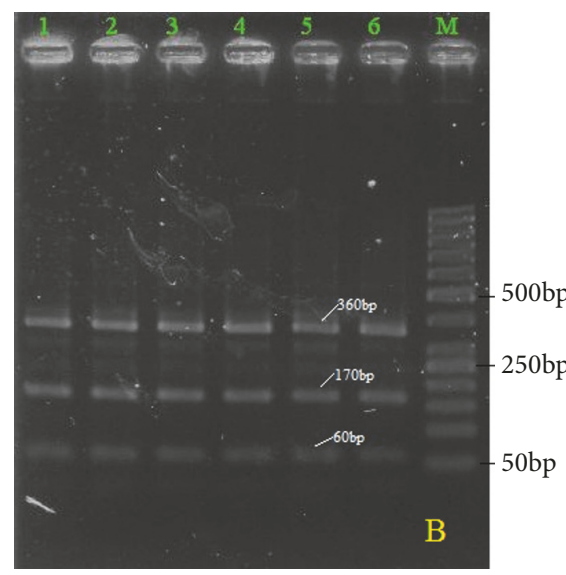

(b)

FIGURE 3: RFLP pattern of PCR products of liver flukes collected from bovine (a) and buffalo (b) in Nghe An province, Vietnam, after digestion with RsaI enzyme. Lane M: 50 bp ladder molecular weight marker; lanes 1, 3, 4, 5, and 7 (a) denoted to those of F. gigantica; lanes 2 and 6 (b) denoted to those of Fasciola sp. (intermediate form); lanes 1-6 (b) denoted to those of F. gigantica.

hepatica, whereas F. gigantica worms had a profile of 360,170 , and $60 \mathrm{bp}$ in size, respectively.

2.5. DNA Sequencing. PCR products of ITS1 from two isolates, 10B-NA1.2 isolated from bovine and 15Tr-NA5 isolated from buffalo, were sent to First BASE Laboratories Sdn Bhdservice (Kembangan 43300, Selangor, Malaysia) for purification and automatic sequencing in both directions, using the same primers which were used in the PCR. Sequences were read on ABI 3130 Genetic Analyzer software (SeqScape 2.1). The accuracy of data was confirmed by two-directional sequencing. Representative sequences were deposited in the GenBank under accession numbers MH790325 and MH790326.

2.6. Sequence and Phylogenetic Analyses. The obtained sequences were analyzed independently by being compared with related sequences available in the GenBank database using BLAST guidelines (http://blast.ncbi.nlm.nih.gov/Blast .cgi). Neighbor joining (NJ) and maximum likelihood (ML) based on Tamura-Nei model phylogenetic tree of ITS1 sequences were constructed using Mega version 7.09 software. Bootstrap analyses (1,000 replications) were carried out to determine the robustness of the finding. rDNA sequences of Paragonimus westermani (AF040935.1) were used as an outgroup.

\section{Results}

3.1. PCR and PCR-RFLP. A region of approximately $680 \mathrm{bp}$ of the ITS1 of rDNA in 96 samples was successfully amplified (Figure 2) as predicted. Negative control did not produce any band on the gels. PCR-RFLP bands profile of Fasciola with restriction enzymes RsaI was performed. The results of PCR products digestion with $R s a \mathrm{I}$ were approximately $60,100 \mathrm{bp}$, and 360bp fragments for F. hepatica; 60, $170 \mathrm{bp}$, and $360 \mathrm{bp}$ for F. gigantica; and 60, 100, 170, and $370 \mathrm{bp}$ for intermediate form (Figure 3).

Table 1 illustrates the identified liver flukes in relation to their origins and their definitive hosts. Accordingly, 96 
TABLE 1: Frequency of F. gigantica and F. hepatica identified by PCR-RFLP in different animal hosts in Vietnam.

\begin{tabular}{lccc}
\hline Host & Bovine & Buffalo & Total number of adult flukes \\
\hline F. gigantica & 5 & 88 & 93 \\
Fasciola sp. & 2 & 1 & 3 \\
F. hepatica & 0 & 0 & 0 \\
\hline Total number & 7 & 89 & 96 \\
\hline
\end{tabular}

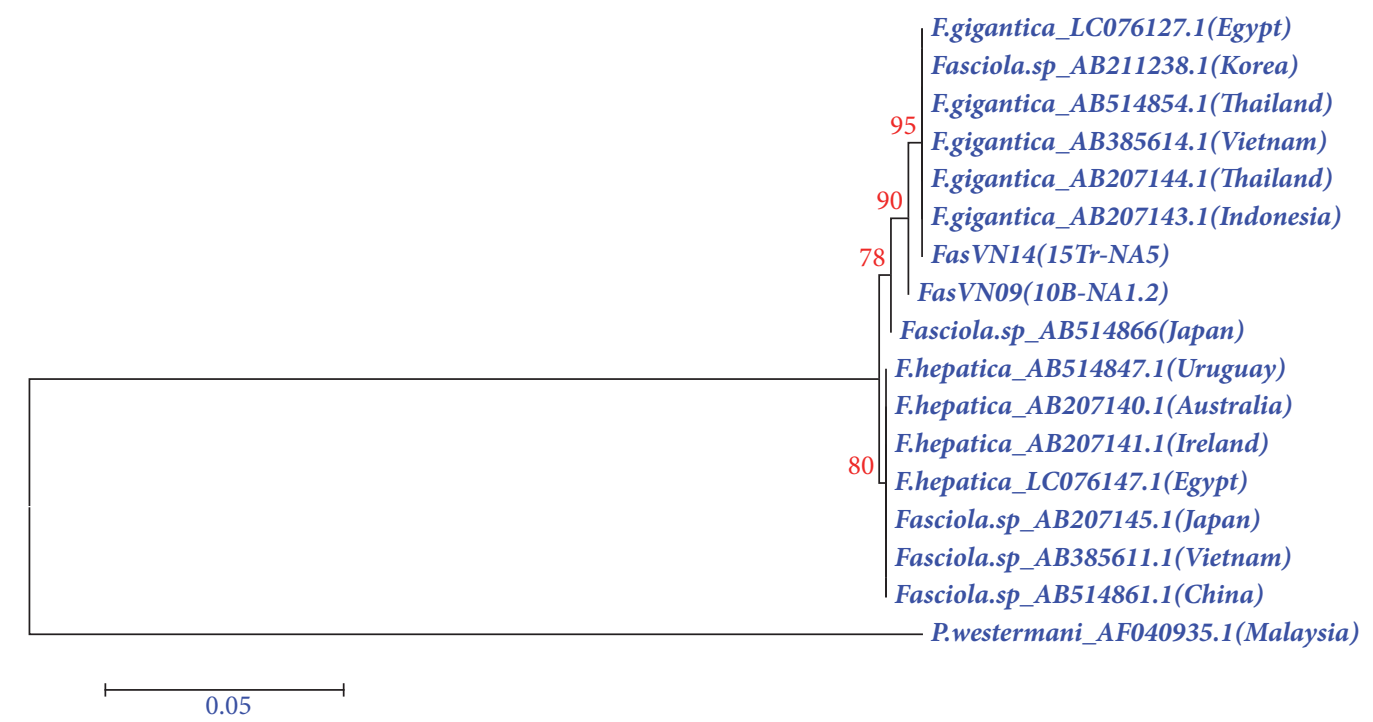

FIGURE 4: Phylogenetic relationship of ITS1 sequences of Fasciola from Vietnam using Neighbor-Joining Tree method. Paragonimus westermani (AF040935.1) was used as the outgroup.

Fasciola isolates were studied from bovine and buffalo of Nghe An province, Vietnam. Out of 96 analyzed specimens from Nghe An province, 93 (96.88\%) flukes were identified as F. gigantica and $3(3.12 \%)$ as intermediate Fasciola (Table 1).

3.2. Complete ITS1 Sequencing of rDNA. DNA sequencing of two ITS1 was complete. BLAST results showed that $F$. gigantica from Thailand (AB207144.1) possessed the sequence most similar to those in these 2 worms with $99.31 \%$ identity for FasVN09 (10B-NA1.2) isolate (MH790325) and 100\% identity for FasVN14 (15Tr-NA5) isolate (MH790326).

Phylogenic tree constructed by using ITS1 sequences of the Fasciola species is shown in Figure 4. All the isolates of Fasciola in different countries clustered together, supported by high bootstrap value $(>78 \%)$. The phylogenetic tree constructed by Neighbor-Joining Tree method supports the blast results by showing similarity between ITS1 sequences (Nghe An province, Vietnam) and ITS1 in Egypt (LC076127.1), Thailand (AB514854.1), Vietnam (AB385614.1), and Indonesia (AB207143.1). The nucleotide sequence data obtained in current study have been deposited in the GenBank under accession numbers MH790326.1 (15Tr-NA5 isolate) and MH790325.1 (10B-NA1.2 isolate).

\section{Discussion}

DNA-based molecular methods are accurate and reliable for understanding the different species of Fasciola and considered control procedures in endemic areas $[13,14]$. PCR-RFLP assay is a powerful method to distinguish between F. hepatica and F. gigantica. In this study, PCR-RFLP based on the partial rDNA of ITS1 and restriction RsaI enzyme was used for differentiation and identification of Fasciola species in Nghe An province. These techniques have been utilized for differentiation among Fasciola species based on the profiles generated by the effects of endonucleases on ITS genes of these parasites [15]. Ichikawa et al. (2011) used RsaI enzyme based on ITS1 region to specifically distinguish F. hepatica and F. gigantica in Myanmar and did not report F. hepatica in their study. In a study in Iran, Aryaeipour et al. (2014) showed that $R s a$ I restriction enzyme may be utilized for the differentiation of two species [16]. Saki et al. (2011) used AvaII and DraII to differentiate between F. hepatica and F. gigantica in 28S DNA [17]. Ghavami et al. (2009) showed that a digested pattern of 230,340, and $341 \mathrm{bp}$ is specific to F. hepatica species and has no effect on F. gigantica [18]. Ashrafi et al. (2004) used ITS2 nucleotide sequencing to identify Fasciola spp. In their study, two species of F. hepatica and F. gigantica were seen in Guilan, northern Iran [19].

Our study did detect F. gigantica and mixed patterns in Nghe An province but not F. hepatica. The results of our study were similar to those of some previous researches in Vietnam [20, 21]. The majority of Fasciolaspecies in this study were molecularly identified as F. gigantica which was concordant with the knowledge that F. gigantica mainly infected buffalo and bovine in Vietnam. In addition the 
hybrid form of Fasciola had been confirmed based on analysis of ITS1 sequence. The intermediate form from a human case and animals had been reported in Vietnam $[10,22]$. The absence of $F$. hepatica in the current study was supported by recent studies of a large number of Fasciola from animals in the country [10] and some neighboring countries such as Myanmar and Thailand [3, 23]. Intermediate Fasciola form has been reported to coexist in areas sympatric for both $F$. hepatica and F. gigantica such as some Asian countries (Japan, Korea, China, and Iran) [12]. In this study, the coexistence of intermediate Fasciola and F. gigantica in the absence of $F$. hepatica was detected in Vietnam as well as in Thailand and Myanmar [3, 23].

\section{Conclusion}

Using ITS1 marker has identified both $F$. gigantica and intermediate form of Fasciola coexisting in the Nghe An province of central Vietnam.

\section{Data Availability}

The data used to support the findings of this study are available from the corresponding author upon request.

\section{Conflicts of Interest}

The authors declare that they have no conflicts of interest.

\section{Acknowledgments}

This study was supported by Vietnam Military Medical University, Hanoi, Vietnam. The results described in this paper were part of KC10.26/06-10 project.

\section{References}

[1] S. Mas-Coma, M. D. Bargues, and M. A. Valero, "Fascioliasis and other plant-borne trematode zoonoses," International Journal for Parasitology, vol. 35, no. 11-12, pp. 1255-1278, 2005.

[2] S. Mas-Coma, M. A. Valero, and M. D. Bargues, "Fasciola, lymnaeids and human fascioliasis, with a global overview on disease transmission, epidemiology, evolutionary genetics, molecular epidemiology and control," Advances in Parasitology, vol. 69, pp. 41-146, 2009.

[3] M. Ichikawa and T. Itagaki, "Molecular analysis of aspermic Fasciola flukes from Korea on the basis of the nuclear ITS1 region and Mitochondrial DNA markers and comparison with Japanese aspermic Fasciola flukes," Journal of Veterinary Medical Science, vol. 74, no. 7, pp. 899-904, 2012.

[4] W. Y. Huang, B. He, C. R. Wang, and X. Q. Zhu, "Characterisation of Fasciola species from Mainland China by ITS-2 ribosomal DNA sequence," Veterinary Parasitology, vol. 120, no. 1-2, pp. 75-83, 2004.

[5] L. Ai, M.-X. Chen, S. Alasaad et al., "Genetic characterization, species differentiation and detection of Fasciola spp. by molecular approaches," Parasites \& Vectors, vol. 4, no. 1, article no. 101, 2011.
[6] T. Itagaki, M. Kikawa, K. Terasaki, T. Shibahara, and K. Fukuda, "Molecular characterization of parthenogenic Fasciola sp. in Korea on the basis of DNA sequences of ribosomal ITS1 and mitochondrial NDI gene," Journal of Veterinary Medical Science, vol. 67, no. 11, pp. 1115-1118, 2005.

[7] A. Marcilla, M. D. Bargues, and S. Mas-Coma, "A PCR-RFLP assay for the distinction between Fasciola hepatica and Fasciola gigantica," Molecular and Cellular Probes, vol. 16, no. 5, pp. 327$333,2002$.

[8] M. Ichikawa and T. Itagaki, "Discrimination of the ITS1 types of Fasciola spp. based on a PCR-RFLP method," Parasitology Research, vol. 106, no. 3, pp. 757-761, 2010.

[9] T. Itagaki, K. Sakaguchi, K. Terasaki, O. Sasaki, S. Yoshihara, and T. Van Dung, "Occurrence of spermic diploid and aspermic triploid forms of Fasciola in Vietnam and their molecular characterization based on nuclear and mitochondrial DNA," Parasitology International, vol. 58, no. 1, pp. 81-85, 2009.

[10] S. Nguyen, S. Amer, M. Ichikawa, T. Itagaki, Y. Fukuda, and Y. Nakai, "Molecular identification of Fasciola spp. (Digenea: Platyhelminthes) in cattle from Vietnam," Parasite, vol. 19, no. 1, pp. 85-89, 2012.

[11] T. D. Bui, P. N. Doanh, C. Saegerman, and B. Losson, "Current status of fasciolosis in Vietnam: An update and perspectives," Journal of Helminthology, vol. 90, no. 5, pp. 511-522, 2016.

[12] T. Itagaki, M. Kikawa, K. Sakaguchi et al., "Genetic characterization of parthenogenic Fasciola sp. in Japan on the basis of the sequences of ribosomal and mitochondrial DNA," Parasitology, vol. 131, no. 5, pp. 679-685, 2005.

[13] M. Peng, M. Ichinomiya, M. Ohtori, M. Ichikawa, T. Shibahara, and T. Itagaki, "Molecular characterization of Fasciola hepatica, Fasciola gigantica, and aspermic Fasciola sp. in China based on nuclear and mitochondrial DNA," Parasitology Research, vol. 105, no. 3, pp. 809-815, 2009.

[14] R. Shafiei, B. Sarkari, and A. Moshfe, "A consistent PCR-RFLP assay based on ITS-2 ribosomal DNA for differentiation of Fasciola species," Iranian Journal of Basic Medical Sciences, vol. 16, no. 12, pp. 1266-1269, 2013.

[15] Y. Dar, S. Amer, A. Mercier, B. Courtioux, and G. Dreyfuss, "Molecular identification of Fasciola spp. (Digenea: Fasciolidae) in Egypt," Parasite, vol. 19, no. 2, pp. 177-182, 2012.

[16] M. Aryaeipour, S. Rouhani, M. Bandehpour, H. Mirahmadi, B. Kazemi, and M. B. Rokni, "Genotyping and phylogenetic analysis of fasciola spp. Isolated from sheep and cattle using PCR-RFLP in Ardabil Province, Northwestern Iran," Iranian Journal of Public Health, vol. 43, no. 10, pp. 1364-1371, 2014.

[17] J. Saki, S. Khademvatan, and E. Yousefi, "Molecular identification of animal Fasciola isolates in southwest of Iran," Australian Journal of Basic and Applied Sciences, vol. 5, no. 11, pp. 1878-1883, 2011.

[18] M. B. Ghavami, P. Rahimi, A. Haniloo, and S. N. Mosavinasab, "Genotypic and phenotypic analysis of fasciola isolates," Iranian Journal of Parasitology, vol. 4, no. 3, pp. 61-70, 2009.

[19] K. Ashrafi, A Survey on Human and Animal Fascioliasis And Genotypic and Phenotypic Characteristics of Fasciolids and their Relationship with Lymnaeid Snails in Gilan Province [Ph.D. thesis], PhD, Tehran University of Medical Sciences, northern Iran, 2004.

[20] T. H. Le, N. Van De, T. Agatsuma et al., "Molecular confirmation that Fasciola gigantica can undertake aberrant migrations in human hosts," Journal of Clinical Microbiology, vol. 45, no. 2, pp. 648-650, 2007. 
[21] T. G. T. Nguyen, N. van de, J. Vercruysse, P. Dorny, and T. H. Le, "Genotypic characterization and species identification of Fasciola spp. with implications regarding the isolates infecting goats in Vietnam," Experimental Parasitology emphasizes, vol. 123, no. 4, pp. 354-361, 2009.

[22] T. H. Le, N. V. De, T. Agatsuma et al., "Human fascioliasis and the presence of hybrid/introgressed forms of Fasciola hepatica and Fasciola gigantica in Vietnam," International Journal for Parasitology, vol. 38, no. 6, pp. 725-730, 2008.

[23] A. Wannasan, P. Khositharattanakool, P. Chaiwong, S. Piangjai, P. Uparanukraw, and N. Morakote, "Identification of Fasciola species based on mitochondrial and nuclear DNA reveals the co-existence of intermediate Fasciola and Fasciola gigantica in Thailand," Experimental Parasitology emphasizes, vol. 146, pp. 64-70, 2014. 


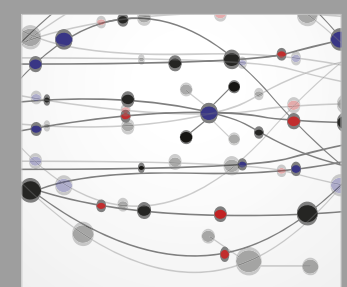

The Scientific World Journal
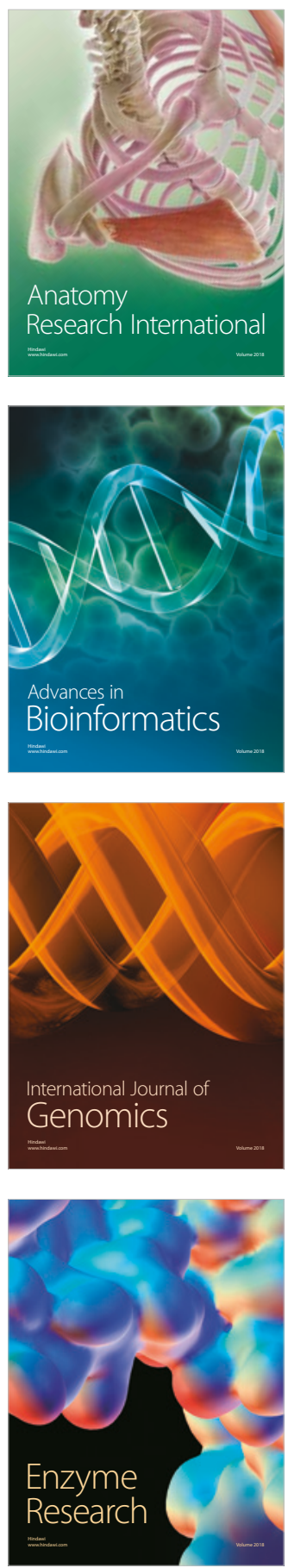
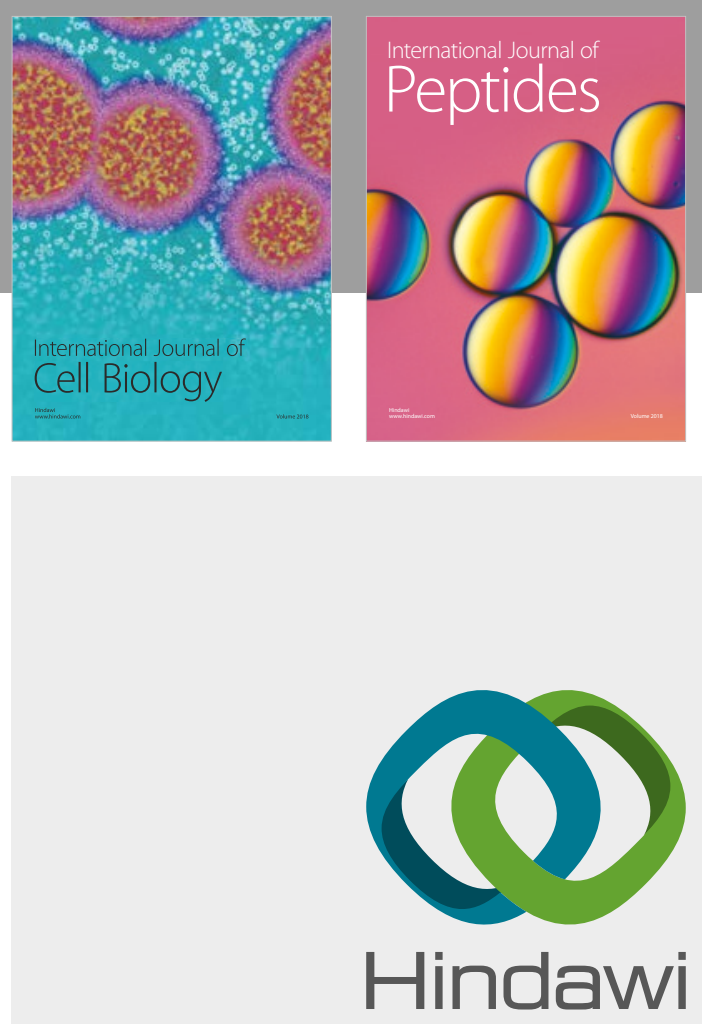

Submit your manuscripts at

www.hindawi.com
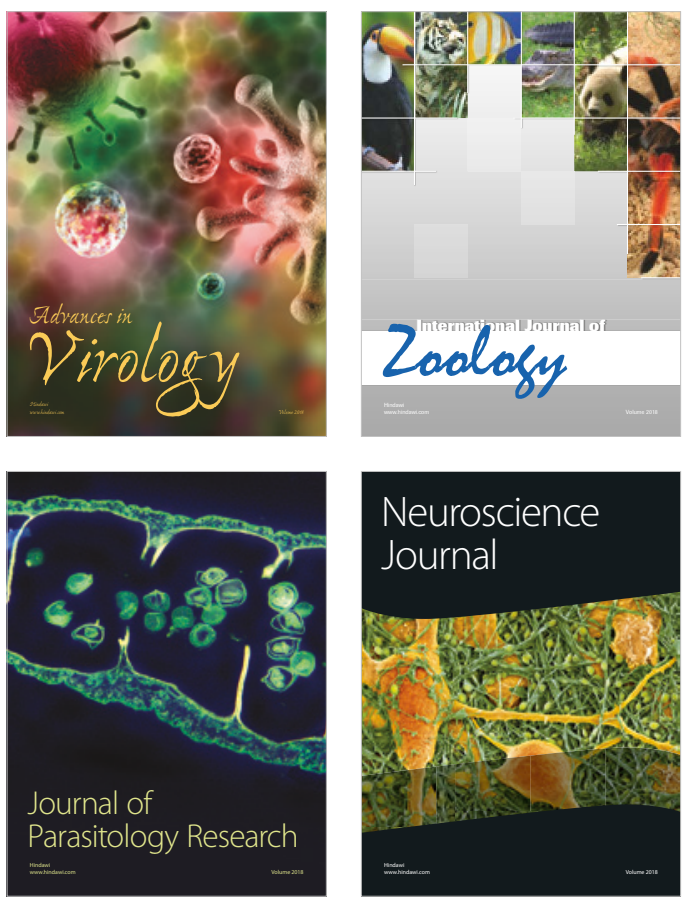
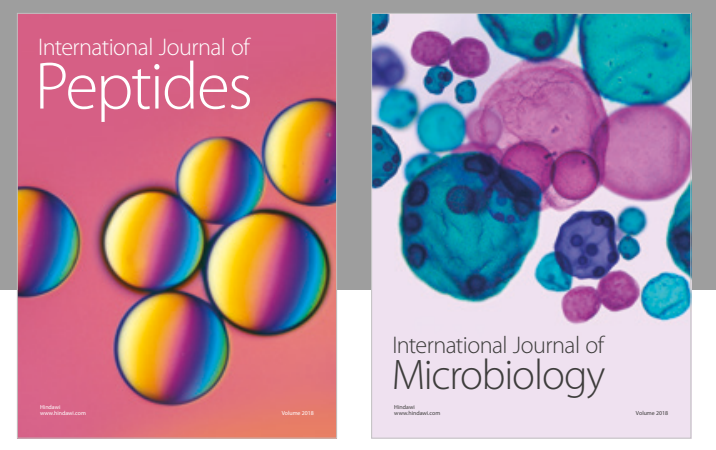

nternational Journal of Microbiology
Journal of
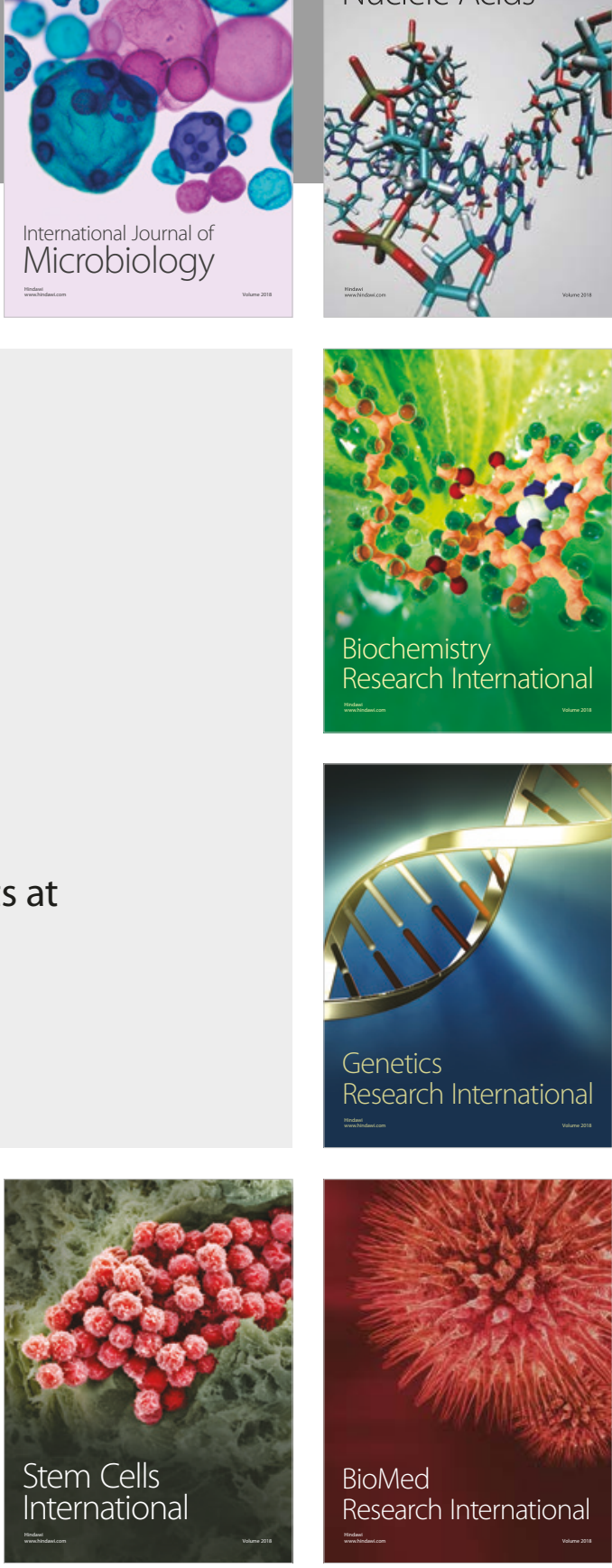
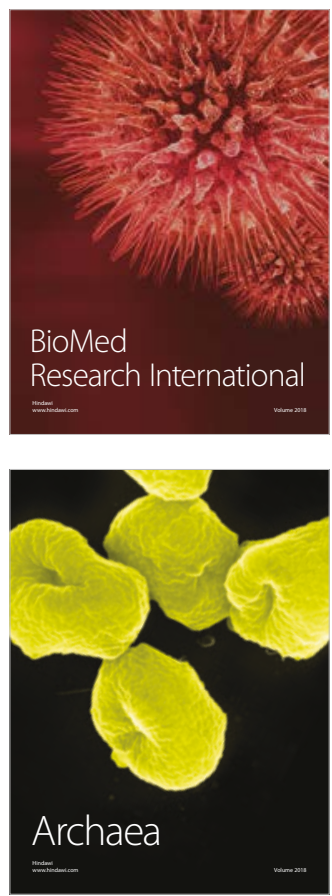